\title{
Colorectal endoscopic submucosal dissection: predictors and neoplasm-related gradients of difficulty
}

\section{다 $(9)$}

\section{Authors}

Federico lacopini ${ }^{1}$, Yutaka Saito ${ }^{2}$, Antonino Bella ${ }^{3}$, Takuji Gotoda ${ }^{4}$, Patrizia Rigato ${ }^{5}$, Walter Elisei ${ }^{1}$, Fabrizio Montagnese $^{1}$, Giampaolo lacopini ${ }^{6}$, Guido Costamagna ${ }^{7}$

\section{Institutions}

1 Gastroenterology Endoscopy Unit, Ospedale S. Giuseppe, Albano Laziale, Rome, Italy

2 Endoscopy Division, National Cancer Center Hospital, Tokyo, Japan

3 National Centre for Epidemiology, Surveillance and Health Promotion, Istituto Superiore di Sanità, Rome, Italy

4 Division of Gastroenterology and Hepatology, Nihon University School of Medicine, Tokyo, Japan

5 Pathology Unit, Ospedale S. Giuseppe, Marino, Rome, Italy

6 Private Practice, Via Merulana, Rome, Italy

7 Surgical Endoscopy Unit, Policlinico Agostino Gemelli, Catholic University, Rome, Italy

submitted 25.11.2016

accepted after revision 19.5.2017

Bibliography

DOI https://doi.org/10.1055/s-0043-113566 |

Endoscopy International Open 2017; 05: E839-E846

(c) Georg Thieme Verlag KG Stuttgart · New York

ISSN 2364-3722

\section{Corresponding author}

Federico lacopini, MD, Gastroenterology Endoscopy Unit, Ospedale S. Giuseppe, Via Olivella km1, Albano Laziale,

Rome 00043, Italy

Fax: +39-06-93273216

federico.iacopini@gmail.com

\section{ABSTRACT}

Background and study aim The role of colorectal endoscopic submucosal dissection (ESD) is standardized in Japan and East Asia, but technical difficulties hinder its diffusion. The aim was to identify predictors of difficulty for each neoplasm type.

Methods A competent operator performed all procedures. ESD difficulty was defined as: en bloc with a slow speed $\left(<0.07 \mathrm{~cm}^{2} / \mathrm{min} ; 30 \times 30 \mathrm{~mm}\right.$ neoplasm in $>90 \mathrm{~min}$ ), conversion to endoscopic mucosal resection, or resection abandonment. Pre- and intraoperative difficulty variables were defined according to standard criteria, and evaluated separately for the rectum and colon. Difficulty predictors and gradients were evaluated by the multivariate logistic regression model.

Results A total of 140 ESDs were included: 110 in the colon and 30 in the rectum. Neoplasms were laterally spreading tumors - granular type (LST-G) in 85 cases (61\%); the median longer axis was $30 \mathrm{~mm}$ (range $15-180 \mathrm{~mm}$ ); a scar was present in 15 cases (11\%). ESD en bloc resection and difficulty rates were $85 \%(n=94)$ and $35 \%(n=39)$ in the colon, and $73 \%(n=22)$ and $50 \%(n=15)$ in the rectum $(P=0.17$ and 0.28 , respectively). The scar was the only preoperative predictor of difficulty in the rectum (odds ratio [OR] 12.3, $95 \%$ confidence interval $[\mathrm{CI}] 1.27-118.36)$, whereas predictors in the colon were: scar (OR 12.7, 95\%Cl 1.15139.24), LST - nongranular type (NG) (OR 10.5, $95 \% \mathrm{Cl}$ $1.20-55.14$ ), and sessile polyp morphology (OR 3.1, $95 \%$ Cl 1.18-10.39). Size $>7-\leq 12 \mathrm{~cm}^{2}$ (OR 0.20 , $95 \% \mathrm{Cl} 0.06-$ 0.74 ) and operator experience $>120$ procedures (OR 0.19 , $95 \% \mathrm{Cl} 0.04-0.81$ ) were predictors for a easy procedure. No intraoperative predictors of difficulty were identified in the rectum, whereas predictors in the colon were: severe submucosal fibrosis (OR 21.9, 95\%Cl 2.11-225.64), ineffective submucosal exposure by gravity countertraction (OR 12.3, 95\% Cl 2.43-62.08), and perpendicular submucosal dissection approach (OR 5.2, 95\%Cl 1.07-25.03). When experience was $/=90$, preoperative gradient of colonic ESD difficulty was the highest for LST-NGs (scar positive and negative up to $47 \%$ and $20 \%$, respectively), intermediate for sessile polyps with scar (up to $23 \%$ ), and the lowest for LST-Gs (<8\%). Different difficulty gradients between neoplasm types persisted with increasing experience: LSTNG rate up to $14 \%$ after 120 procedures.

Conclusions Colonic and rectal ESD difficulty has qualitative differences. Preoperative predictors should be considered to identify the difficulty gradient of each neoplasm type and the appropriate setting for ESD. 


\section{Introduction}

Endoscopic submucosal dissection (ESD) achieves higher en bloc and curative resection rates than endoscopic mucosal resection (EMR), minimizing the risk of residual lesions and inaccurate microstaging, as well as the need for surveillance and reintervention [1]. ESD has an official role in the treatment algorithm of most colorectal neoplasms in Japan and East Asia [1], but this is not the case in Western countries, where it is performed proficiently in few centers, and only advised for neoplasms in the easy and safe rectal location or when with submucosal invasion [2].

The identification of factors predictive for a difficult colorectal ESD would improve its adoption and change the management of superficial colorectal neoplasms. Previous studies are from Japan and are not generalizable. Moreover, data are partially discordant owing to a mix of assessments between preand intraoperative variables [3-7], and the inclusion of operators with heterogeneous experience levels $[3-5,8,9]$. The aim of the current study was to evaluate the whole spectrum of predictors of colorectal ESD difficulty and provide difficulty gradients for each neoplasm type.

\section{Methods}

\section{Design and population}

This was an observational study based on a prospective database of consecutive patients with nonpedunculated neoplasms considered for ESD in a nonacademic hospital from January 2012 to July 2015.

Inclusion criteria were intraepithelial neoplasia or superficial submucosal cancers with a diameter $>20 \mathrm{~mm}$ or a scar from a previous resection characterized by chromoendoscopy with indigo carmine (0.5\%) and narrow-band imaging [1].

Exclusion criteria were: deep submucosal invasion diagnosed by distorted pit (Kudo's type V) and/or capillary (Sano's type III) patterns in a demarcated area [10]; short patient life expectancy (Charlson comorbidity index $\geq 8$ ) [11] or poor general condition (American Society of Anesthesiologists score $\geq 3$ ); variations in ESD technique; inability to provide informed consent.

The institutional review board approved the study in accordance with the ethical principles of the Declaration of Helsinki. Patients were informed of ESD, operator level of expertise, and therapeutic alternatives (EMR and surgery).

\section{ESD technique}

ESDs were performed by a single operator (F.I.) who achieved competence in colorectal ESD in terms of en bloc resection rate $(>80 \%)$ and operating speed [12]. Midazolam and fentanyl were used for sedation. A pediatric colonoscope with waterjet system (PCF-H180Al; Olympus, Tokyo, Japan), a small-calibertip transparent hood (ST-hood; Fujifilm, Tokyo, Japan), and carbon dioxide insufflation were used in all procedures. A mixture of $250 \mathrm{~mL}$ hydroxyethyl starch (Voluven; Fresenius Kabi, Isola della Scala, Italy), $1 \mathrm{mg}$ epinephrine, and $4 \mathrm{mg}$ indigo carmine was injected into the submucosa for lesion lifting. The electrosurgical VIO200 generator unit (ERBE, Tübingen, Germany) was set at endocut I (effect 2, duration 3, interval 1) for mucosal incision, and swift coagulation (effect 4, 40 W) for submucosal dissection and hemostasis. A short $1.5 \mathrm{~mm}$ knife (DualKnife; Olympus) was possibly the only knife used.

Sodium hyaluronate solution 0.4\% (Sigmavisc; Hyaltec, Bagnolet, France) was injected if lesion lifting was poor. An insulated knife (ITknife-nano; Olympus) was used if the submucosal dissection approach was perpendicular. Hemostatic forceps (Coagrasper; Olympus) were used if hemostasis by the knife in use was ineffective.

In cases where ESD had to be abandoned (failures), a conversion to EMR (representing a hybrid ESD/EMR procedure) was considered. Resection was defined as en bloc when the lesion was resected in a single piece. Completeness of resection was assessed by chromoendoscopy and narrow-band imaging. The specimen area was calculated assuming the shape as an ellipsis ( $\pi \cdot$ long axis.short axis/4). The operating time was recorded as speed (specimen area/operating time, $\mathrm{cm}^{2} / \mathrm{min}$ ), as measured from submucosal injection to the end of dissection. No time restriction was set. Synchronous neoplasms underwent ESD in separate sessions.

\section{Histology}

Specimens were cut into $3 \mu \mathrm{m}$ slices, and stained with hematoxylin and eosin. En bloc resection was defined as: complete (R0) if horizontal and vertical margins were tumor-free [13]; incomplete (R1) if the margins were tumor-positive; undetermined $(R x)$ if margins were not evaluable owing to coagulation artifacts [1]. Diagnosis was in accordance with the Vienna classification [14]. Resection was defined as curative when all of the following criteria were present: tumor differentiation well/ moderate (G1/G2); submucosal invasion depth < $1000 \mu \mathrm{m}$; lymphovascular invasion negative; budding absent/low grade [1]. The definition of curative resection was applicable to R0 and $\mathrm{R} 1$ resections with horizontal margins positive or undetermined for dysplasia [15].

\section{Outcomes}

The primary outcome was the identification of predictors of ESD difficulty defined as: en bloc with a slow operating speed $\left(<0.07 \mathrm{~cm}^{2} / \mathrm{min}\right.$, equivalent to the resection of $30 \times 30 \mathrm{~mm}$ neoplasm in $>90 \mathrm{~min}$ ) [15]; conversion to a hybrid ESD/EMR or abandonment of resection (ESD failures).

The secondary outcome was the association between predictors of difficulty and adverse events. Adverse events were defined as intraprocedural, early (within 24 hours post-ESD), and late (2-30 days post-ESD). Bleeding was an adverse event if it led to ESD failure, hospital admission, and/or urgent colonoscopy. Perforation was diagnosed as full-thickness wall defect and/or extra-intestinal air on computed tomography without wall defects during the endoscopic resection. Electrocoagulation syndrome was defined as postoperative abdominal pain and/or fever $\geq 37.6^{\circ} \mathrm{C}$ in the absence of perforation 6 hours after the procedure. 


\section{ESD difficulty variables}

Predictors were grouped into preoperative and intraoperative variables. Preoperative variables were:

- patient age and sex;

- neoplasm morphology: laterally spreading tumor - granular type (LST-G), LST - nongranular type (LST-NG), sessile polyp [16];

- superficial patterns: regular (Kudo's types III/IV and/or Sano's type II) or distorted (Kudo's type Vi and/or Sano's type IIIA) [10];

- area size: $\leq 7 \mathrm{~cm}^{2},>7-\leq 12 \mathrm{~cm}^{2},>12 \mathrm{~cm}^{2}$ (longer axis of respective circle areas: $\leq 30 \mathrm{~mm},>31-\leq 40 \mathrm{~mm},>40 \mathrm{~mm}$ ) $[4,7,9]$;

- presence of a scar from a previous endoscopic or surgical resection [16];

- colon location: right or left (at and distal from the splenic flexure) $[17,18]$;

- rectal location: perineal or pelvic when the distal margin of the neoplasm was $<3 \mathrm{~cm}$ or $>3 \mathrm{~cm}$ above the dentate line, respectively [19];

- semilunar fold location when proximal side of the neoplasm was invisible in the straightforward position [18, 20];

- operator experience, stratified in consecutive groups of 30 colorectal ESDs, starting from $n=61$ (previous 60 procedures were performed during the learning curve) [12].

Intraoperative variables were:

- submucosal fibrosis: absent (F0), mild (F1), severe (F2) [21];

- lesion lifting: good or poor with the need to inject sodium hyaluronate [7];

- bleeding frequency, according to the number of hemostatic forceps applications: low $(<10)$ or high $(>10)[3]$;

- scope control: direct or paradoxical [3, 4];

- submucosal dissection approach: tangential or perpendicular with the need of the ITknife-nano to avoid muscle injury [3];

- submucosal exposure by gravity countertraction: effective or ineffective despite changes in patient decubitus [20].

\section{Statistical analysis}

Categorical variables were summarized by absolute frequency and percentage, and compared by the chi-squared or Fisher's exact test. Continuous variables were summarized by median and range, and compared by parametric $t$ test for two groups (ANOVA test for three or more groups) or nonparametric Mann-Whitney test (Kruskal-Wallis test for three or more groups). The Shapiro-Wilk test was used to test the normality of the distribution. Statistical analyses were based on number of neoplasms. Odds ratios (OR) and $95 \%$ confidence intervals $(95 \% \mathrm{Cl})$ were calculated using cross tables in the univariate analysis.

Associations between ESD difficulty and predictive variables were tested by a logistic regression model in enrolled patients. Variables were included in the multivariate model and retained in the final model if the $P$ value was $<0.15$ on univariate analysis. The models for the colon and rectum were built separately,
- Table 1 Neoplasm-based clinicopathological features of 140 superficial colorectal cancers treated by endoscopic submucosal dissection.

\begin{tabular}{|c|c|c|c|}
\hline & $\begin{array}{l}\text { Colon } \\
n=110\end{array}$ & $\begin{array}{l}\text { Rectum } \\
n=30\end{array}$ & $P$ value \\
\hline $\begin{array}{l}\text { Age, median (range), } \\
\text { years }\end{array}$ & $67(44-87)$ & $66(48-84)$ & 0.91 \\
\hline Sex, female, n (\%) & $42(38)$ & $15(50)$ & 0.30 \\
\hline Morphology, n (\%) & & & 0.26 \\
\hline - LST-G & $64(58)$ & $21(70)$ & \\
\hline - LST-NG & $35(32)$ & $5(17)$ & \\
\hline - Sessile polyp & $11(10)$ & $4(13)$ & \\
\hline Area size, $\mathrm{cm}^{2}$ & & & 0.50 \\
\hline - $\leq 7$ & $52(47)$ & $12(40)$ & \\
\hline - $>7-\leq 12$ & $32(29)$ & $10(33)$ & \\
\hline . $>12$ & $26(24)$ & $8(27)$ & \\
\hline $\begin{array}{l}\text { Superficial patterns: } \\
\text { distorted, } \mathrm{n}(\%)\end{array}$ & $4(4)$ & $3(10)$ & 0.17 \\
\hline Scar positive, n (\%) & $7(6)$ & $8(27)$ & 0.004 \\
\hline $\begin{array}{l}\text { Location: semilunar } \\
\text { fold, } \mathrm{n}(\%)\end{array}$ & $78(71)$ & $8(27)$ & $<0.001$ \\
\hline Location, n (\%) & $\begin{array}{l}\text { Right } 76 \text { (69) } \\
\text { Left } 34 \text { (31) }\end{array}$ & $\begin{array}{l}\text { Pelvic } 16(53) \\
\text { Perineal } 14 \\
\text { (47) }\end{array}$ & $\mathrm{N} / \mathrm{A}$ \\
\hline
\end{tabular}

LST, laterally spreading tumor; G, granular type; NG, nongranular type; $\mathrm{N} / \mathrm{A}$, not applicable.

and in two steps to analyze preoperative variables only, and pre- and intraoperative variables together. Results of the logistic regression model were used to calculate preoperative probabilities of ESD difficulty (\%) according to the following formula: $\operatorname{Pr}($ ESD difficulty $)=(1 /[1+\exp (-\beta x)])[22]$. Associations of preand intraoperative predictors and of predictors with adverse events were evaluated by chi-squared or Fisher's exact test. $P$ values $<0.05$ were considered to be significant.

All analyses were performed using STATA software (version 11.2; StataCorp, College Station, Texas, USA).

\section{Results}

\section{Patient and neoplasm features}

A total of 165 neoplasms in 155 patients were considered for ESD. In total, 25 neoplasms were excluded because of technique variations $(n=18)$, estimated deep submucosal invasion $(n=6)$, and short life expectancy $(n=1)$. Therefore, 140 ESDs in 130 patients were included. A median of 20 procedures was performed every 6 months: $15(11 \%)$ in the first and $29(21 \%)$ in the last 6-month period.

Neoplasms were located in the colon and rectum in 110 and 30 cases, respectively ( $\triangleright$ Table 1 ). No significant differences in morphology and size were observed between colonic 
- Table 2 Endoscopic submucosal dissection results.

\begin{tabular}{|c|c|c|c|}
\hline & $\begin{array}{l}\text { Colon } \\
n=110\end{array}$ & $\begin{array}{l}\text { Rectum } \\
\mathrm{n}=\mathbf{3 0}\end{array}$ & $P$ value \\
\hline ESD difficulty & & & 0.33 \\
\hline - Easy - en bloc + high speed & $71(65)$ & $15(50)$ & \\
\hline $\begin{array}{l}\text { - Difficult } \\
\text { - En bloc + low speed } \\
\text { - Conversion to hybrid } \\
\text { ESD/EMR } \\
\text { - } \text { Abandoned }\end{array}$ & $\begin{array}{c}23(21) \\
12(11) \\
4(4)\end{array}$ & $\begin{array}{l}7(23) \\
5(17) \\
3(10)\end{array}$ & \\
\hline Causes of failure & & & 0.22 \\
\hline - Submucosal fibrosis & 10 & 4 & \\
\hline - Intolerance & 4 & 4 & \\
\hline - Bleeding & 1 & - & \\
\hline - Perforation & 1 & - & \\
\hline $\begin{array}{l}\text { Gravity countertraction: } \\
\text { ineffective }\end{array}$ & $24(22)$ & $1(3)$ & 0.02 \\
\hline Submucosal fibrosis & & & 0.045 \\
\hline - $F 1$ & $22(20)$ & $5(17)$ & \\
\hline - $F 2$ & $12(11)$ & $8(27)$ & \\
\hline Bleeding frequency: high & $6(5)$ & $5(17)$ & 0.06 \\
\hline Lesion lifting: poor & $9(8)$ & $6(20)$ & 0.09 \\
\hline $\begin{array}{l}\text { Submucosal approach: } \\
\text { perpendicular }\end{array}$ & $23(21)$ & $9(30)$ & 0.33 \\
\hline Scope control: paradoxical & $12(11)$ & $2(7)$ & 0.73 \\
\hline \multicolumn{4}{|c|}{$\begin{array}{l}\text { ESD, endoscopic submucosal dissection; EMR, endoscopic mucosal resec- } \\
\text { tion. }\end{array}$} \\
\hline
\end{tabular}

and rectal neoplasms: LST-G was the most prevalent morphology (85 [61\%]); the median longer axis was $30 \mathrm{~mm}$ (range 15 $180 \mathrm{~mm})$; $<20 \mathrm{~mm}$ in 7 neoplasms (5\%) and $>40 \mathrm{~mm}$ in 25 (18\%). A total of 15 lesions (11\%) had a scar from previous EMR or surgery. Neoplasms on a semilunar fold were significantly more frequent in the colon than the rectum $(P<001)$; those with a scar were significantly more frequent in the rectum $(P=0.004)$.

\section{ESD results}

ESD was completed en bloc in 116 cases ( $83 \%$ ) within a mean of $74 \pm 44$ minutes (range $20-240$ minutes), and failed in 24 cases after a mean of $86 \pm 39$ minutes (range $20-150$ minutes). ESD en bloc resection and difficulty rates were $85 \%(n=94)$ and $35 \%$ $(n=39)$ in the colon, and $73 \%(n=22)$ and $50 \%(n=15)$ in the rectum ( $P=0.17$ and 0.28 , respectively). Difficult ESD rates according to definition subgroups as well as causes of failure were not different in the colon and rectum ( $\triangleright$ Table 2 ). R0 and curative resections of colonic and rectal ESDs were similar: $\mathrm{R} 0$ resections $82(87 \%)$ vs. 18 ( $82 \%)(P=0.501)$; curative resections 88 (94\%) vs. 21 (95\%) ( $P>0.99)$.

After conversion to hybrid ESD/EMR $(n=17)$, complete resection was achieved in all cases (piecemeal in 15 [88\%]). Cura- tive resection by hybrid ESD/EMR was achieved in eight cases $(67 \%)$ in the colon and in four cases $(80 \%)$ in the rectum. After ESD was abandoned $(n=7)$, six patients underwent surgery and one patient underwent ESD in deep sedation. T1 cancers were diagnosed in 15 neoplasms (11\%): 8 ESDs (7\%); 5 hybrid ESD/ $\operatorname{EMR}(29 \%) ; 2$ surgery $(29 \%)(P=0.008)$.

\section{Preoperative predictors and probabilities of difficulty}

Univariate analysis for rectal ESD showed that the scar was the only variable predictive of difficulty ( $\vee$ Table 3 ). Multivariate analysis for colonic ESD ( $\triangleright$ Table 3 ) showed that predictors were, with decreasing odds ratios: the scar; LST-NG and sessile polyp morphology; operator experience $\leq 120$ procedures. Patient age increase and neoplasm size $>7-\leq 12 \mathrm{~cm}^{2}$ were predictors of a easy colonic ESD.

The probabilities of a difficult ESD of specific colonic neoplasm types are reported in - Fig. 1. LST-NGs were the most difficult: the rate increased up to $19.7 \%$ for scar-negative and $47.0 \%$ for scar-positive cases when operator experience was < 90 procedures, and remained $>10 \%$ for scar-positive cases when experience was $>120$ procedures. Sessile polyps showed an intermediate $22.8 \%$ difficulty gradient if scar positive and experience was $<90$, which decreased to $<10 \%$ when experience was $>120$. LST-Gs were the easiest neoplasm type: their difficulty gradient was $<10 \%$ regardless of the presence of a scar or the level of experience.

\section{Intraoperative predictors}

Univariate analysis for rectal ESD difficulty did not identify any significant predictive variables ( $\$$ Table 4 ). However, all cases with severe (F2) fibrosis and poor lifting were difficult procedures, and ineffective submucosal exposure by gravity countertraction occurred in only one easy case, thus impeding a statistical analysis. The multivariate logistic regression model for coIonic ESD difficulty showed that intraoperative predictors were, with decreasing odds ratios: severe submucosal fibrosis; ineffective submucosal exposure by gravity countertraction; perpendicular submucosal approach ( Table 4).

\section{Association between the pre- and intraoperative predictors of a difficult colonic ESD}

Morphology showed an association with severe submucosal fibrosis (LST-G 3\%; LST-NG $17 \%$; sessile polyp 36\%; $P=0.004$ ) and perpendicular submucosal dissection approach (sessile polyp 9\%; LST-G $14 \%$; LST-NG $37 \% ; P=0.02$ ). The presence of a scar was not associated with severe submucosal fibrosis (scar positive $29 \%$; scar negative $10 \%$; $P=0.17$ ) but was associated with submucosal fibrosis per se (scar positive $86 \%$; scar negative $27 \% ; P=0.005)$. A trend toward a significant association was found between size and ineffective submucosal exposure by gravity countertraction $\left(\leq 7 \mathrm{~cm}^{2} 15 \%\right.$; $>7-\leq 12 \mathrm{~cm}^{2}$ $19 \%$; $\left.>12 \mathrm{~cm}^{2} 38 \% ; P=0.06\right)$. No association was found between ESD experience and any intraoperative predictor. 
- Table 3 Preoperative predictors of endoscopic submucosal dissection difficulty ( $\mathrm{n}=130$ patients).

\begin{tabular}{|c|c|c|c|}
\hline & \multicolumn{2}{|l|}{ Colon } & \multirow{2}{*}{$\begin{array}{l}\text { Rectum } \\
\text { Univariate analysis } \\
\text { OR ( } 95 \% \mathrm{Cl})\end{array}$} \\
\hline & $\begin{array}{l}\text { Univariate analysis } \\
\text { OR }(95 \% \mathrm{Cl})\end{array}$ & $\begin{array}{l}\text { Multivariate analysis } \\
\text { OR }(95 \% \mathrm{CI})\end{array}$ & \\
\hline Male sex & $1.07(0.49-2.36)$ & - & $0.77(0.18-3.21)$ \\
\hline Age (continuous) & $0.94(0.89-0.98)$ & $0.94(0.88-0.99)$ & $0.95(0.87-1.04)$ \\
\hline \multicolumn{4}{|l|}{ Morphology } \\
\hline - LST-G & 1 & & 1 \\
\hline - LST-NG & $3.60(0.97-13.41)$ & $10.49(1.20-55.14)$ & $5.33(0.51-56.24)$ \\
\hline - Sessile & $4.50(1.86-10.87)$ & $3.51(1.18-10.39)$ & $1.33(0.16-11.36)$ \\
\hline \multicolumn{4}{|l|}{ Scar } \\
\hline - Negative & 1 & & 1 \\
\hline - Positive & $10.70(1.24-92.34)$ & $12.68(1.15-139.24)$ & $12.25(1.27-118.36)$ \\
\hline \multicolumn{4}{|l|}{ Size area, $\mathrm{cm}^{2}$} \\
\hline . $\leq 7$ & 1 & & 1 \\
\hline . $>7-\leq 12$ & $0.15(0.05-0.44)$ & $0.20(0.06-0.74)$ & $0.21(0.04-1.31)$ \\
\hline . $>12$ & $0.42(0.16-11.11)$ & $0.47(0.13-1.68)$ & $0.50(0.08-3.13)$ \\
\hline \multicolumn{4}{|l|}{ Superficial patterns } \\
\hline - Regular & 1 & & 1 \\
\hline - Distorted & $4.95(0.50-49.22)$ & - & $0.46(0.04-5.75)$ \\
\hline Location, segments & $\begin{array}{l}\text { Left: } 1 \\
\text { Right: } 0.88(0.39-2.01)\end{array}$ & - & $\begin{array}{l}\text { Pelvic: } 1 \\
\text { Perineal: } 3.00(0.68-13.31)\end{array}$ \\
\hline \multicolumn{4}{|c|}{ Location: semilunar fold } \\
\hline - No & 1 & & 1 \\
\hline - Yes & $0.76(0.33-1.76)$ & - & $1.00(0.20-5.04)$ \\
\hline \multicolumn{4}{|c|}{ Experience, procedures } \\
\hline - $61-90$ & 1 & & 1 \\
\hline - $91-120$ & $0.33(0.10-1.12)$ & $0.27(0.06-1.18)$ & $0.53(0.06-4.91)$ \\
\hline - $121-150$ & $0.28(0.08-0.95)$ & $0.19(0.04-0.81)$ & $3.20(0.25-41.21)$ \\
\hline - $151-180$ & $0.17(0.05-0.60)$ & $0.08(0.02-0.41)$ & $0.80(1.00-6.35)$ \\
\hline . $181-200$ & $0.18(0.04-0.78)$ & $0.12(0.02-0.84)$ & $0.20(0.02-2.58)$ \\
\hline
\end{tabular}

\section{Adverse events}

A total of 16 adverse events occurred in 15 procedures (11\%): $12(11 \%)$ in the colon and $4(13 \%)$ in the rectum $(P=0.75)$. Intraprocedureal perforations occurred in 4 ESDs $(3 \%)$, always in the colon. Three perforations were full thickness $(<5 \mathrm{~mm})$ and were closed by clips: two patients recovered uneventfully, and one asymptomatic patient underwent early surgery as a result of an incomplete resection. One perforation was diagnosed by abdominal pain, pneumoperitoneum, and pneumoscrotum after ESD of a $60 \mathrm{~mm}$ sessile polyp in the transverse colon. No perforation was visible at endoscopy and the resection site was too large to be closed by clips. The pneumoperitoneum was evacuated and the patient was managed conservatively. Electrocoagulation syndrome occurred after 10 procedures (7\%) and resolved conservatively. Delayed bleeding occurred in two procedures ( $1 \%$ ) after 7 days: bleeding stopped spontaneously in one colonic ESD, and endoscopic hemostasis was performed in one rectal case.

Adverse event rates were not significantly different in not difficult and difficult colonic (19\% vs. $38 \% ; P=0.36$ ) and rectal ( $27 \%$ vs. $25 \%$; $P=0.60$ ) ESDs. No association was found between predictors of difficulty and adverse events. 


\begin{tabular}{|l|l|l|l|l|l|l|}
\hline \multicolumn{2}{|l}{ Morphology } & \multicolumn{2}{l|}{ Scar negative } & \multicolumn{2}{l|}{ Scar positive } \\
\cline { 2 - 7 } Experience & LST-G & Sessile & LST-NG & LST-G & Sessile & LST-NG \\
\hline$\leq 90$ & $<0.7$ & $<2.3$ & $0.7^{\dagger}-19.7^{*}$ & $<7.8$ & $2.8^{\dagger}-22.8^{* \ddagger}$ & $7.9^{\dagger}-47.0^{* \ddagger}$ \\
\hline $91-120$ & $<0.2$ & $<0.6$ & $<1.9$ & $<2.3$ & $<7.5$ & $2.3^{\dagger}-19.6^{* \ddagger}$ \\
\hline$>120$ & $<0.1$ & $<0.4$ & $<1.3$ & $<1.6$ & $<5.3$ & $1.6^{\dagger}-14.3^{* \ddagger}$ \\
\hline
\end{tabular}

LST, laterally spreading tumor; G, granular type; NG, nongranular type.

In overlapping gradients: *Size $\leq 7 \mathrm{~cm}^{2}$, †Size $>7-\leq 12 \mathrm{~cm}^{2}$, ${ }^{\dagger}$ Size $>12 \mathrm{~cm}^{2}$.

Fig. 1 Preoperative probabilities (\%) of a difficult colonic endoscopic submucosal dissection. Colors correspond to difficulty gradients: $<10 \%$ (white), $10 \%-19 \%$ (blue), $20 \%-39 \%$ (yellow), $\geq 40 \%$ (red). The range of difficulty rates is related to differences between size categories.

- Table 4 Intraoperative predictors of a difficult endoscopic submucosal dissection ( $n=130$ patients).

\begin{tabular}{|c|c|c|c|}
\hline & \multicolumn{2}{|l|}{ Colon } & \multirow{2}{*}{$\begin{array}{l}\text { Rectum } \\
\text { Univariate analysis } \\
\text { OR }(95 \% \mathrm{Cl})\end{array}$} \\
\hline & $\begin{array}{l}\text { Univariate analysis } \\
\text { OR }(95 \% \mathrm{CI})\end{array}$ & $\begin{array}{l}\text { Multivariate analysis } \\
\text { OR ( } 95 \% \mathrm{Cl})\end{array}$ & \\
\hline \multicolumn{4}{|l|}{ Bleeding frequency } \\
\hline - Low & 1 & & 1 \\
\hline - High & $0.77(0.13-4.39)$ & - & $1.63(0.23-11.46)$ \\
\hline \multicolumn{4}{|l|}{ Scope control } \\
\hline - Direct & 1 & & 1 \\
\hline - Paradoxical & $1.65(0.50-5.49)$ & - & $1.00(0.06-17.62)$ \\
\hline \multicolumn{4}{|l|}{ Lesion lifting } \\
\hline - Good & 1 & & 1 \\
\hline - Poor & $6.32(1.24-32.04)$ & - & $\mathrm{N} / \mathrm{A}$ \\
\hline \multicolumn{4}{|c|}{ Submucosal approach } \\
\hline - Tangential & 1 & & 1 \\
\hline - Perpendicular & $6.65(2.35-18.76)$ & $5.16(1.07-25.03)$ & $0.73(0.15-3.49)$ \\
\hline \multicolumn{4}{|c|}{ Gravity countertraction } \\
\hline - Good & 1 & & 1 \\
\hline - Ineffective & $3.45(1.35-8.85)$ & $12.29(2.43-62.08)$ & N/A \\
\hline \multicolumn{4}{|c|}{ Submucosal fibrosis } \\
\hline - F0 & 1 & & 1 \\
\hline - F1 & $1.41(0.53-3.76)$ & $0.89(0.16-4.83)$ & $1.36(0.37-5.00)$ \\
\hline - F2 & $6.12(1.52-24.60)$ & $21.87(2.11-225.64)$ & $\mathrm{N} / \mathrm{A}$ \\
\hline
\end{tabular}

\section{Discussion}

This study indicates that ESD difficulty is qualitatively different in the colon and rectum. This result was obtained by separating the analysis of the two locations and it is more clinically relevant than the identification of the colon as a further difficulty predictor. Preoperative predictors in the colon were morphology, size and the scar of a previous resection, the latter was rele- vant also in the rectum. Similarly, intraoperative predictors in the colon were ineffective submucosal exposure by gravity countertraction and perpendicular submucosal dissection approach, whereas severe (F2) submucosal fibrosis was relevant in both locations.

The scar was the most important preoperative predictor of ESD difficulty. This observation agrees with Hori et al. [17] but not other Authors, who considered the scar a morphological ca- 
tegory $[7,17,20]$, and/or included less-severe scars from biopsies $[3,4,7,9,20]$ or small case numbers $[7,20]$. The scar was associated with submucosal fibrosis, the greatest intraoperative predictor of difficulty in this and previous studies [3-7], as well as of perforation $[3,5,18,23,24]$. The warning against attempting and leaving an endoscopic resection incomplete needs to be reinforced $[25,26]$.

LST-NG and sessile polyp morphologies were the second most relevant predictors of colonic ESD difficulty. Similar results have been attributed to a higher prevalence of submucosal fibrosis in these morphological categories [6, 20,27]. However, morphology and severe submucosal fibrosis were both independent predictors in the present study and other concurrent causes should be considered.

Stratification of size into three groups showed that small $\left(\leq 7 \mathrm{~cm}^{2}\right.$ or with the longer diameter $\left.\leq 30 \mathrm{~mm}\right)$, and large colonic neoplasms ( $>12 \mathrm{~cm}^{2}$ or with the longer diameter $>40 \mathrm{~mm}$ ) configure difficult ESDs. The paradoxical greater difficulty of small lesions was also observed by Inada et al. [6]. This observation may be related to the inclusion of the operating speed in the definition of ESD difficulty: the time needed to create the mucosal flap and gain the submucosal access may be independent of size. Conversely, the greater ESD difficulty of large lesions could be related to an impaired recognition of the bowel wall profile during submucosal dissection, owing to lumen tortuosity and mucosal flap wrapping.

Operator experience was the third preoperative predictor of a difficult colonic ESD. Inada et al. [6] observed that experience was indirectly related to the difficulty rate but did not evaluate its predictive yield. Other Authors have shown different difficulty rates between trainees and experts [7, 15, 20, 28]. In the current study, the exclusion of the first 60 colorectal ESDs required to achieve competency [12] avoided an underestimation of difficulty predictors $[8,9]$. Moreover, the subsequent 140 procedures represent a sample size large enough to cover the experience span of most Western endoscopists $[3,7,20,27]$ and demonstrate odds ratio variations.

The identification of two intraoperative predictors of a difficult colonic ESD (submucosal fibrosis and ineffective submucosa exposure by gravity countertraction) confirms that the complete difficulty evaluation requires both pre- and intraoperative variables [3-7, 20,27]. However, a preoperative estimation is much more relevant as it may avoid exposing the patient to intraoperative risks [22]. The stepwise application of the logistic regression model and the combination of the odds ratios of the preoperative predictors in assessment charts allowed the identification of gradients of ESD difficulty for specific colonic neoplasms. LST-NGs showed the highest gradient (up to $47 \%$ ) regardless of the presence of a scar and size; sessile polyps showed an intermediate gradient (up to $23 \%$ ) if associated with a scar and experience is $<90$ procedures; LST-Gs showed the lowest gradient $(<10 \%)$. The greater ESD difficulty of LSTNG persisted even after a large case volume. It is noteworthy that absolute indications for ESD (i. e. LST-NG and scar-positive neoplasms) identified by the Japanese Gastrointestinal Endoscopy Society and European Society of Gastrointestinal Endoscopy $[1,2]$ showed the highest difficulty gradients. Ancillary maneuvers/approaches for submucosal dissection (clip-line/ band countertraction, pocket creation method [29,30], knives with a scissor shape or waterjet function [31]) should be anticipated for difficult neoplasms, as well as allowing extra time for the endoscopy session. Alternatively, very difficult neoplasms should be directed to referral centers to guarantee the best outcomes.

Methodological heterogeneities prevent direct comparisons with previous studies and are responsible for the wide 4\%-59\% range in colorectal ESD difficulty rates. Definitions of ESD difficulty were based either on piecemeal and/or incomplete resections [3-5], perforation [20], and operating time thresholds ranging from 90 minutes to 150 minutes regardless lesion size. The definition used in the present study comprised both ESD failure and operating speed, which makes time independent from size and avoids defining large lesions as difficult "a priori" $[4,7,9,17]$. The overall $3 \%$ perforation rate in colorectal ESD is at the lower end of the $2 \%-20 \%$ range in the literature $[7,17$, $23]$, and no association was found between adverse events and predictors of ESD difficulty. The inclusion of two not difficult ESDs with perforation in the difficult group would not have changed the results. A standard definition of colorectal ESD difficulty is warranted: difficulty rates of specific neoplasm types should be considered as key performance indicators, with implications for patient safety, skill certification, and reimbursement.

This study has some limitations. Magnification was not used for characterization introducing a bias in neoplasm selection, but the $11 \%$ rate of invasive cancer is similar to the $14 \%$ in Japanese studies, with magnification (range 10\%-23\%) [3,4,20] and without magnification (range $6 \%-12 \%$ ) $[5,6,9,18]$. The enrollment of a single endoscopist reduces the generalizability of the present results as well as of previous studies [3, 4, 17, 27]. However, groups of heterogeneous endoscopists (trainees and experts) $[6,20]$, top-level experts [3-5, 18,27], or trainees [8, 9] may represent a limitation as well. The small rectal neoplasm sample size may be responsible for some difference between rectal and colonic predictors, but the present series is the largest from a Western country [32,33] and proportions of colonic and rectal cases reflect epidemiological data similar to other studies. Finally, the strengths of the study are the short study period, the unchanged ESD technique, and a high annual volume of procedures $(n=40)$, which is similar to most Japanese experiences $[3,4,17,27,28]$.

In conclusion, colonic and rectal ESD have qualitative differences and specific predictors of difficulty. The use of assessment charts to predict the preoperative ESD difficulty gradient of each neoplasm type may be recommended to choose the most appropriate setting in order to achieve the best outcomes.

\section{Competing interests}

None 


\section{References}

[1] Tanaka S, Kashida H, Saito Y et al. JGES guidelines for colorectal endoscopic submucosal dissection/endoscopic mucosal resection. Dig Endosc 2015; 27: 417 - 434

[2] Pimentel-Nunes P, Dinis-Ribeiro M, Ponchon T et al. Endoscopic submucosal dissection: European Society of Gastrointestinal Endoscopy (ESGE) Guideline. Endoscopy 2015; 47: 829-854

[3] Hayashi N, Tanaka S, Nishiyama S et al. Predictors of incomplete resection and perforation associated with endoscopic submucosal dissection for colorectal tumors. Gastrointest Endosc 2014; 79: 427 435

[4] Sato K, Ito S, Kitagawa T et al. Factors affecting the technical difficulty and clinical outcome of endoscopic submucosal dissection for colorectal tumors. Surg Endosc 2014; 28: 2959-2965

[5] Isomoto H, Nishiyama H, Yamaguchi $\mathrm{N}$ et al. Clinicopathological factors associated with clinical outcomes of endoscopic submucosal dissection for colorectal epithelial neoplasms. Endoscopy 2009; 41: $679-683$

[6] Inada Y, Yoshida N, Kugai M et al. Prediction and treatment of difficult cases in colorectal endoscopic submucosal dissection. Gastroenterol Res Pract 2013; 2013: 523084

[7] Takeuchi Y, lishi H, Tanaka S et al. Factors associated with technical difficulties and adverse events of colorectal endoscopic submucosal dissection: retrospective exploratory factor analysis of a multicenter prospective cohort. Int J Colorect Dis 2014; 29: 1275-1284

[8] Agapov M, Dvoinikova E. Factors predicting clinical outcomes of endoscopic submucosal dissection in the rectum and sigmoid colon during the learning curve. Endosc Int Open 2014; 2: E235-240

[9] Shiga $\mathrm{H}$, Endo K, Kuroha $\mathrm{M}$ et al. Endoscopic submucosal dissection for colorectal neoplasia during the clinical learning curve. Surg Endosc 2014; 28: 2120-2128

[10] Matsuda T, Fujii T, Saito Y et al. Efficacy of the invasive/non-invasive pattern by magnifying chromoendoscopy to estimate the depth of invasion of early colorectal neoplasms. Am J Gastroenterol 2008; 103 : $2700-2706$

[11] Chang CM, Yin WY, Wei CK et al. Adjusted age-adjusted Charlson Comorbidity Index score as a risk measure of perioperative mortality before cancer surgery. PloSOne 2016; 11: doi:10.1371/journal. pone.0148076 (Published online 2016 Feb 5)

[12] lacopini F, Bella A, Costamagna G et al. Stepwise training in rectal and colonic endoscopic submucosal dissection with differentiated learning curves. Gastrointest Endosc 2012; 76: 1188-1196

[13] Morino M, Risio M, Bach S et al. Early rectal cancer: the European Association for Endoscopic Surgery (EAES) clinical consensus conference. Surg Endosc 2015; 29: 755 - 773

[14] Dixon MF. Gastrointestinal epithelial neoplasia: Vienna revisited. Gut 2002; 51: $130-131$

[15] Nakajima T, Saito Y, Tanaka S et al. Current status of endoscopic resection strategy for large, early colorectal neoplasia in Japan. Surg Endosc 2013; 27: 3262 - 3270

[16] [Anonymous]. The Paris endoscopic classification of superficial neoplastic lesions: esophagus, stomach, and colon: November 30 to December 1, 2002. Gastrointest Endosc 2003; 58: 3-43

[17] Hori K, Uraoka T, Harada K et al. Predictive factors for technically difficult endoscopic submucosal dissection in the colorectum. Endoscopy 2014; 46: $862-870$
[18] Mizushima T, Kato M, Iwanaga I et al. Technical difficulty according to location, and risk factors for perforation, in endoscopic submucosal dissection of colorectal tumors. Surg Endosc 2015; 29: 133 -139

[19] Iacopini F, Gotoda T, Elisei W et al. Heterotopic gastric mucosa in the anus and rectum: first case report of endoscopic submucosal dissection and systematic review. Gastroenterol Rep 2016; 4: 196 - 205

[20] Imai K, Hotta K, Yamaguchi Y et al. Preoperative indicators of failure of en bloc resection or perforation in colorectal endoscopic submucosal dissection: implications for lesion stratification by technical difficulties during stepwise training. Gastrointest Endosc 2016; 83: 954-962

[21] Matsumoto A, Tanaka S, Oba S et al. Outcome of endoscopic submucosal dissection for colorectal tumors accompanied by fibrosis. Scand J Gastroenterol 2010; 45: 1329-1337

[22] Hirasawa K, Kokawa A, Oka $\mathrm{H}$ et al. Risk assessment chart for curability of early gastric cancer with endoscopic submucosal dissection. Gastrointest Endosc 2011; 74: 1268-1275

[23] Kim ES, Cho KB, Park KS et al. Factors predictive of perforation during endoscopic submucosal dissection for the treatment of colorectal tumors. Endoscopy 2011; 43: 573-578

[24] Hong SN, Byeon JS, Lee BI et al. Prediction model and risk score for perforation in patients undergoing colorectal endoscopic submucosal dissection. Gastrointest Endosc 2016; 84: 98 - 108

[25] Kobayashi N, Saito Y, Sano Y et al. Determining the treatment strategy for colorectal neoplastic lesions: endoscopic assessment or the non-lifting sign for diagnosing invasion depth? Endoscopy 2007; 39: $701-705$

[26] Moss A, Bourke M], Williams S] et al. Endoscopic mucosal resection outcomes and prediction of submucosal cancer from advanced colonic mucosal neoplasia. Gastroenterology 2011; 140: 1909-1918

[27] Toyonaga T, Man-i M, Fujita T et al. Retrospective study of technical aspects and complications of endoscopic submucosal dissection for laterally spreading tumors of the colorectum. Endoscopy 2010; 42: $714-722$

[28] Saito Y, Uraoka T, Yamaguchi Y et al. A prospective, multicenter study of 1111 colorectal endoscopic submucosal dissections (with video). Gastrointest Endosc 2010; 72: 1217-1225

[29] Yamasaki Y, Takeuchi Y, Uedo $\mathrm{N}$ et al. Traction-assisted colonic endoscopic submucosal dissection using clip and line: a feasibility study. Endosc Int Open 2016; 4: E51 - 55

[30] Hayashi Y, Sunada K, Takahashi H et al. Pocket-creation method of endoscopic submucosal dissection to achieve en bloc resection of giant colorectal subpedunculated neoplastic lesions. Endoscopy 2014; 46: (Suppl. 01): E421-422

[31] Yamamoto K, Michida T, Nishida T et al. Colorectal endoscopic submucosal dissection: recent technical advances for safe and successful procedures. World J Gastrointest Endosc 2015; 7: 1114-1128

[32] De Ceglie A, Hassan C, Mangiavillano B et al. Endoscopic mucosal resection and endoscopic submucosal dissection for colorectal lesions: a systematic review. Crit Rev Oncol Hematol 2016; 104: 138-155

[33] Sauer M, Hildenbrand R, Oyama T et al. Endoscopic submucosal dissection for flat or sessile colorectal neoplasia $>20 \mathrm{~mm}$ : a European single-center series of 182 cases. Endoscopy Int Open 2016; 4: E895900 